\title{
Regression of Labrador keratopathy following cataract extraction
}

\author{
ELIE DAHAN, JEFFREY JUDELSON, AND NEVILLE H WELSH
}

From the Department of Ophthalmology, University of the Witwatersrand, Johannesburg, and St John's Eye Unit, Baragwanath Hospital, Johannesburg, South Africa.

SUMMARY Labrador keratopathy (LK) is an acquired corneal degeneration thought to be caused by chronic exposure to solar irradiation. Reports so far suggest that it is a progressive or at least a stationary condition. There are no detailed reports on recommended therapy. A prospective clinical study was conducted to show regression of LK following extracapsular cataract extraction. Seventeen black patients ( 26 eyes) with LK and mature cataracts underwent extracapsular cataract extraction. The severity of the LK was recorded photographically pre- and postoperatively. The follow-up ranged from 6 to fifteen months. Twenty-four eyes $(92 \%)$ showed regression of the LK. The reduction in exposure to ultraviolet light as a result of aphakic photophobia could be one of the factors which have led to the regression of the LK.

Labrador keratopathy (LK) is an acquired disease in people who have spent most of their lives outdoors exposed to ultraviolet irradiation. ${ }^{1-6}$ Various authors have given different names to the same condition, which is found throughout the world. ${ }^{2-6}$ Freedman ${ }^{2}$ in his classical paper has shown that the clinical appearances and pathological changes in all cases are similar, differing only in severity. There is an almost unanimous opinion among the authors that climatic conditions and aging are the main factors of this acquired corneal degeneration, ${ }^{235-8}$ whereas histopathological findings are still inconclusive..$^{3579}$ The work of Johnson ${ }^{6}$ has recently contributed to the understanding of the pathophysiology of the formation of the droplets on the superficial cornea. Johnson suggests that solar irradiation acts on plasma proteins present in the cornea, degrading them so that they accumulate in the superficial cornea. ${ }^{6}$ Very little has been said on the treatment of LK. Sunglasses and artificial tears are suggested for lesser degree of LK, and for advanced cases superficial keratectomy and lamellar corneal grafts may be indicated. ${ }^{34}$

Since LK occurs mainly in the elderly, ${ }^{2356}$ lens opacities are a common associated finding. Previously we postponed cataract surgery in patients

Correspondence to Dr E Dahan, Department of Ophthalmology, Medical School, York Road, Parktown, Johannesburg 2193, South Africa. with moderate and severe LK, since visual impairment was predominantly due to the corneal pathology. We therefore did not expect any improvement in vision following lens extraction in patients with preoperative visual acuity of counting fingers or better due to severe LK. In exceptional cases, where bilateral mature cataracts were present and preoperative vision was limited to light perception in both eyes, a cataract extraction was performed.

In September 1983 a 65-year-old black male with a left intumescent cataract and a shallow anterior chamber was admitted for cataract extraction. For the four years prior to admission he had been known to suffer from progressive bilateral severe LK. His right eye had an incipient cataract with $2 / 60$ vision and the left eye had light perception only. A planned left extracapsular cataract extraction was performed.

The patient was discharged after an uneventful postoperative course on betamethasone-neomycin drops (Betnesol $\mathbf{N}$ ) four times a day, with atropine $1 \%$ drops twice daily. Eight weeks later, he returned to our outpatient clinic for routine follow-up. Although he expressed his satisfaction at the improved visual acuity in the left eye, he complained of not being able to sit outside in the sun as had been his habit prior to the operation. On slit-lamp examination there were significant regression of the LK bilaterally. This surprising finding led us to plan a prospective clinical study of the effect of cataract extraction on LK. 
Table 1 Analysis of 17 patients with $L K$ undergoing cataract extraction

\begin{tabular}{lc}
\hline Number of Patients & 17 \\
Number of operated eyes & 26 \\
Males & 16 \\
Females & 1 \\
Age in years & $58-87$ \\
Range & $76 \cdot 4$ \\
Mean & No. of eyes \\
& \\
Preoperative staging of LK & - \\
Stage 1 & $3(12 \%)$ \\
Stage 2 & $10(38 \%)$ \\
Stage 3 & $8(31 \%)$ \\
Stage 4 & $5(19 \%)$ \\
Stage 5 & \\
\hline
\end{tabular}

\section{Materials and materials}

Between January 1984 and March 1985 patients with LK and cataracts with best corrected visual acuity of $6 / 60$ or less were admitted for cataract extraction. Patients with other associated diseases such as glaucoma were excluded from the study. Seventeen black patients ( 26 eyes) were included in the prospective clinical study. All patients except one were males with an age range from 58 years to 76 years and a mean age of 67.4 years (Table 1 ).

Preoperative photographs of the anterior segments in both eyes were taken with a Zeiss slit-lamp camera. In order to standardise the grading of the corneal pathology the severity of the LK was assessed by the three authors concomitantly according to a modification of Freedman's classification ${ }^{3}$ as follows.

Stage 1. Small oil-like droplets are seen in the corneal epithelium, beginning at the limbus in the interpalpebral area. The central corneal epithelium is not yet involved. Vision is not yet impaired. This stage is difficult to demonstrate photographically.

Stage 2. This is characterised by the spreading of

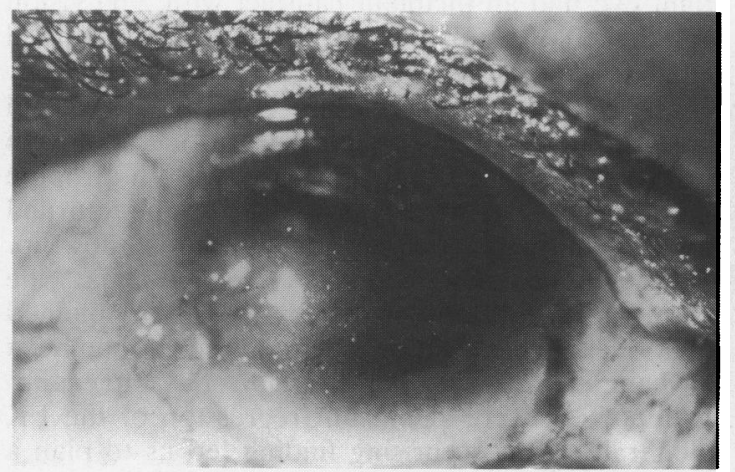

Fig. 1 Case 17, right eye two days after extracapsular cataract extraction. Note the elevated nodules, LK stage 3.

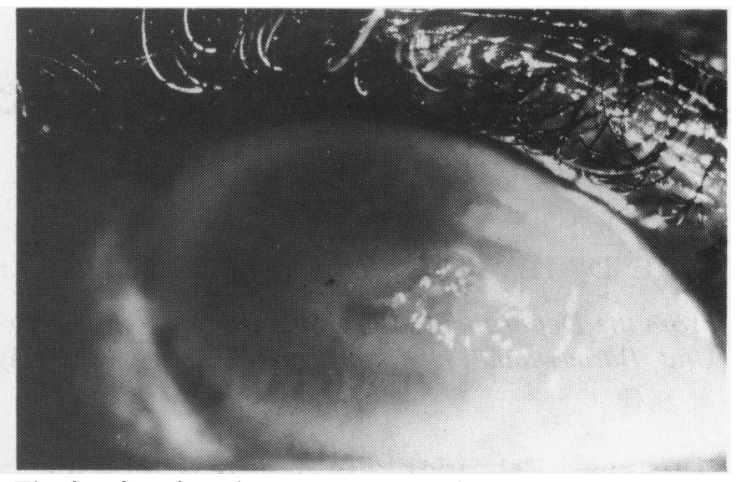

Fig. 2 Case 3, right eye preoperatively. Note the elevated nodules with corneal ulceration, LK stage 4.

these droplets across the cornea to involve the epithelium of the central area and the lower half of the cornea. Vision is $6 / 12$ or less. In some cases there is pigment migration from the conjunctiva on to the cornea in the interpalpebral area.

Stage 3. This is characterised by an increase in the size of the droplets, which begin to invade the deeper part of the epithelium and the superficial parts of the stroma. These droplets now form yellow nodules which protrude above the surface of the epithelium. Vision is $6 / 24$ or less (Fig. 1).

Stage 4. In this stage the nodular swellings erode through the epithelium, causing deep ulcers involving epithelium and stroma. Corneal sensation is diminished or absent in the involved area and vision is severely impaired (6/60 or less). The lesions remain painless and the cornea is not vascularised (Figs. 2, 3).

Stage 5. The corneal lesions become denser and deeper and the involved cornea shows vascularisation which is a result of recurrent secondary infections. Vision is less than 1/60 (Fig. 4).

A planned extracapsular cataract extraction was

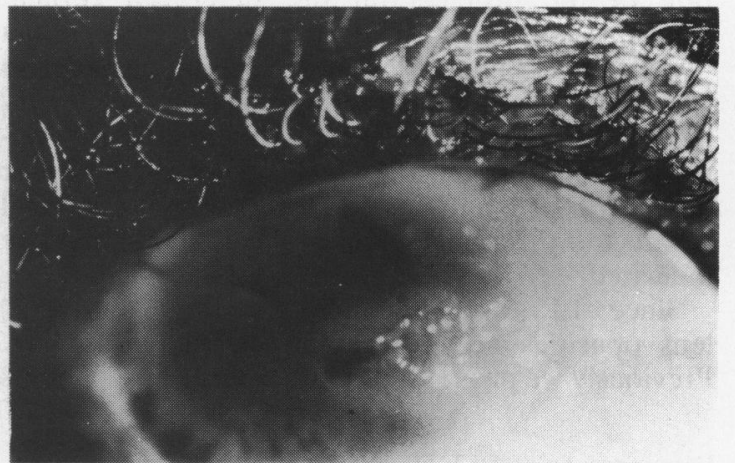

Fig. 3 Case 3, right eye, two days after extracapsular cataract extraction. LK stage 4 is still present. 


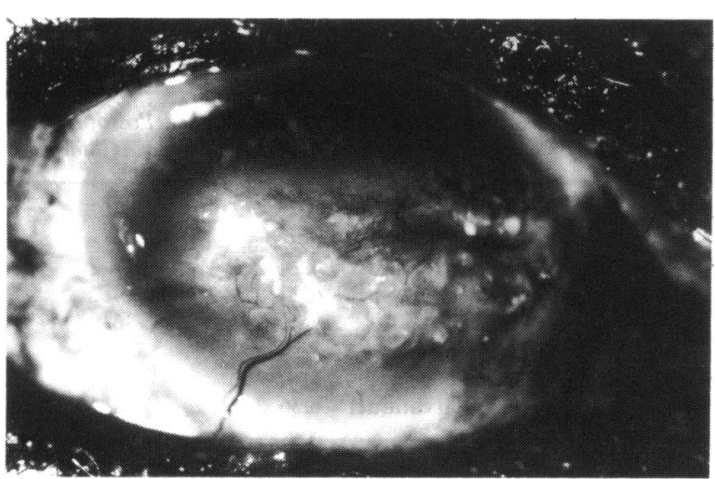

Fig. 4 Case 7, right eye. LK stage 5 showing densely packed nodules with vascularisation due to recurrent infections.

performed with the posterior capsule always being left intact. In LK stages 4 and 5 it was difficult to see the anterior capsule, so a broad sector iridectomy was done. In two cases where visualisation was particularly difficult a secondary aspiration of residual lens material was performed two days after the first operation. In those patients who underwent bilateral cataract extraction the interval between the two operations was less than one week. The patients were discharged a week after surgery with topical medica- tion of Maxitrol drops (neomycin, polymgxin B, dexamethasone) four times a day for six weeks and atropine $1 \%$ drops twice daily for three months. The patients were supplied with non-tinted aphakic spectacles and returned for follow-up at two weeks and thereafter monthly for a minimum period of six months. At each visit anterior segment photographs of the eyes were taken, and staging of the LK was recorded following the criteria listed above. During the follow-up period there was no access to the preoperative staging. At the end of the clinical study the three authors relied on the photographs to confirm the pattern of the regression of the LK.

\section{Results}

Table 2 shows the results. There were 17 patients ( 26 eyes) who underwent extracapsular cataract extraction. Of these, nine patients (18 eyes) had bilateral cataract extraction. Twenty four eyes out of $26(92 \%)$ showed regression of the LK following extracapsular cataract extraction. Table 3 shows the regression pattern of each stage postoperatively. The majority of cases improved to stage 2 , in which only superficial corneal scars are left and visual acuity is markedly improved. These results show that there was a significant improvement in the corneal condition

Table 2 Staging of LK pre-and postcataract extraction

\begin{tabular}{|c|c|c|c|c|c|c|c|}
\hline \multirow[t]{2}{*}{ Case } & \multirow[t]{2}{*}{$\begin{array}{l}\text { Eye } \\
(R, L)\end{array}$} & \multirow[t]{2}{*}{$\begin{array}{l}\text { Age } \\
\text { (years) }\end{array}$} & \multicolumn{2}{|l|}{ Sex } & \multirow[t]{2}{*}{$\begin{array}{l}\text { Preoperative } \\
\text { VAC staging }\end{array}$} & \multirow[t]{2}{*}{$\begin{array}{l}\text { Postoperative } \\
\text { VAC staging }\end{array}$} & \multirow[t]{2}{*}{$\begin{array}{l}\text { Follow-up } \\
\text { (months) }\end{array}$} \\
\hline & & & Male & Female & & & \\
\hline 1 & L & 58 & $\mathbf{M}$ & & LP 4 & $6 / 182$ & 9 \\
\hline 2 & $\mathbf{R}$ & 74 & $\mathbf{M}$ & & $3 / 603$ & $6 / 182$ & 6 \\
\hline \multirow[t]{2}{*}{3} & $\mathbf{R}$ & 65 & $\mathbf{M}$ & & $2 / 604$ (fig. 2) & $6 / 182$ (fig. 5) & 10 \\
\hline & L & & & & LP 4 & $6 / 18 \quad 2$ & 10 \\
\hline \multirow[t]{2}{*}{4} & $\mathbf{R}$ & 64 & $\mathbf{F}$ & & $6 / 602$ & $6 / 122$ & 6 \\
\hline & $\mathbf{L}$ & & & & $6 / 602$ & $6 / 122$ & 6 \\
\hline \multirow[t]{2}{*}{5} & $\mathbf{R}$ & 70 & $\mathbf{M}$ & & LP 3 & $6 / 242$ & 15 \\
\hline & L & & & & $1 / 603$ & $6 / 182$ & 15 \\
\hline 6 & $\mathbf{R}$ & 75 & $\mathbf{M}$ & & LP 4 & $6 / 363$ & 9 \\
\hline \multirow[t]{2}{*}{7} & $\mathbf{R}$ & 65 & $\mathbf{M}$ & & LP 5 (fig. 4) & $1 / 604$ & 10 \\
\hline & L & & & & LP 5 & $3 / 604$ & 10 \\
\hline 8 & L & 61 & $\mathbf{M}$ & & $6 / 603$ & $6 / 182$ & 14 \\
\hline \multirow[t]{2}{*}{9} & $\mathbf{R}$ & 58 & $\mathbf{M}$ & & $3 / 603$ & $6 / 122$ & 6 \\
\hline & L & & & & LP 3 & $6 / 182$ & 6 \\
\hline \multirow[t]{2}{*}{10} & $\mathbf{R}$ & 70 & $\mathbf{M}$ & & $6 / 602$ & $6 / 9 \quad 1$ & 6 \\
\hline & $\mathbf{L}$ & & & & LP 4 & $6 / 363$ & 6 \\
\hline \multirow[t]{2}{*}{11} & $\mathbf{R}$ & 71 & $\mathbf{M}$ & & LP 3 & $6 / 182$ & 6 \\
\hline & L & & & & $6 / 603$ & $6 / 182$ & 6 \\
\hline \multirow[t]{2}{*}{12} & $\mathbf{R}$ & 76 & $\mathbf{M}$ & & HM 5 & $3 / 604$ & 7 \\
\hline & $\mathbf{L}$ & & & & LP 5 & $2 / 604$ & 7 \\
\hline \multirow[t]{2}{*}{13} & $\mathbf{R}$ & 69 & $\mathbf{M}$ & & $3 / 604$ & $6 / 363$ & 14 \\
\hline & L & & & & $6 / 603$ & $6 / 243$ & 14 \\
\hline 14 & $\overline{\mathbf{R}}$ & 65 & $\mathbf{M}$ & & $2 / 604$ & $6 / 363$ & 7 \\
\hline 15 & L & 68 & $\mathbf{M}$ & & LP 5 & $6 / 603$ & 9 \\
\hline 16 & $\mathbf{L}$ & 62 & $\mathbf{M}$ & & LP 4 & $6 / 363$ & 6 \\
\hline 17 & $\mathbf{R}$ & 74 & $\mathbf{M}$ & & $1 / 603$ (fig. 1) & $6 / 91$ (fig. 6) & 6 \\
\hline
\end{tabular}

$\mathrm{VAC}=$ visual acuity with correction. $\mathrm{LP}=$ light perception. $\mathrm{HM}=$ hand movements. 
Table 3 Distribution of postoperative staging of $L K$

\begin{tabular}{|c|c|c|c|c|c|c|}
\hline \multirow{2}{*}{$\begin{array}{l}\text { Preoperative } \\
\text { staging }\end{array}$} & \multirow{2}{*}{$\begin{array}{l}\text { No. of } \\
\text { eyes }\end{array}$} & \multicolumn{5}{|c|}{ Postoperative results } \\
\hline & & Stage I & Stage 2 & Stage 3 & Stage 4 & Stage 5 \\
\hline Stage 1 & - & & & & & \\
\hline Stage 2 & 3 & 1 & 2 & - & - & - \\
\hline Stage 3 & 10 & 1 & 8 & 1 & - & - \\
\hline Stage 4 & 8 & - & 3 & 5 & - & - \\
\hline Stage 5 & 5 & - & - & 1 & 4 & - \\
\hline
\end{tabular}

following extracapsular cataract extraction $(\mathrm{p}<0 \cdot 01)$.

Patients who had unilateral cataract extraction (Table 4) showed concomitant regression in the fellow eye in three out of six eyes (cases 1,16 , and 17). Two eyes were phthisical and could not be assessed and three eyes (cases 6, 8 and 14) showed no alteration.

\section{Discussion}

Previous papers on LK have dealt mainly with its clinical description, epidemiology, incidence, aetiology, and histopathology. Very little is known about the treatment of this condition. Therapeutic measures recommended for LK include sunglasses, ocular lubricants, superficial keratectomy, and lamellar keratoplasty in advanced cases. ${ }^{3}$ However, there have been no detailed reports on these therapeutic measures. So far the condition has been thought to be progressive or stationary. ${ }^{5}$ There have been no previous reports on the regression of LK.

The results of our prospective clinical study have demonstrated a regression of the LK following extracapsular cataract extraction. The regression became evident between eight weeks and four months postoperatively. The most dramatic improvement occurred in the patients at stages 3 and 4 , who

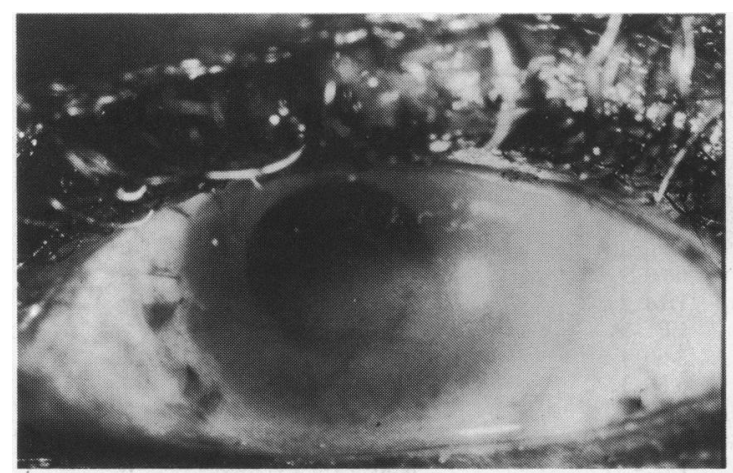

Fig. 5 Case 3, right eye 12 weeks postoperatively. Note regression of the LK to stage 2 with residual superficial corneal scarring.
Table 4 Staging of LK in the unoperated eye pre-and postcataract extraction in the fellow eye

\begin{tabular}{|c|c|c|c|c|}
\hline Case & $\begin{array}{l}\text { Eye } \\
(R, L)\end{array}$ & $\begin{array}{l}\text { Condition of the } \\
\text { unoperated eye }\end{array}$ & $\begin{array}{l}\text { Preoperative } \\
\text { VAC staging }\end{array}$ & $\begin{array}{l}\text { Postoperative } \\
\text { VAC staging }\end{array}$ \\
\hline 1 & $\mathbf{R}$ & Dislocated lens & LP 4 & $6 / 602$ \\
\hline 2 & $\mathbf{L}$ & Phthisical eye & $-\quad-$ & $-\quad-$ \\
\hline 6 & $\mathbf{L}$ & Incipient cataract & $6 / 242$ & $6 / 242$ \\
\hline 8 & $\mathbf{R}$ & Incipient cataract & $6 / 242$ & $6 / 242$ \\
\hline 14 & $\mathbf{L}$ & Aphakic & $6 / 362$ & $6 / 362$ \\
\hline 15 & $\mathbf{R}$ & Phthisical & $-\quad-$ & $-\quad-$ \\
\hline 16 & $\mathbf{R}$ & Incipient cataract & $6 / 604$ & $6 / 242$ \\
\hline 17 & $\mathbf{L}$ & Incipient cataract & $6 / 363$ & $6 / 241$ \\
\hline
\end{tabular}

$\mathrm{VAC}=$ visual acuity with correction $. \mathrm{LP}=$ light perception.

regressed to stage 2 with marked improvement in visual acuity (Tables 2 and 4). Patients with stage 5 regressed generally minimally and those with stage 2 either remained the same postoperatively (case 4) or regressed to stage 1 (case 10). Therefore the regression of LK at the ends of the spectrum of the disease was less spectacular, both in eyes operated upon and those not operated upon.

The improvement in LK could have been due to a number of factors. Reduction in exposure to sunlight is important, since the relation between LK and exposure to ultraviolet irradiation is well documented..$^{2-6}$ Most of the patients in our clinical study came from the Northern Transvaal, in which the average annual duration of sunshine expressed as a percentage of possible sunshine is $80 \%$. They were all edlerly, and their occpation and lifestyle had resulted in chronic exposure to solar irradiation. Aphakic photophobia is a well known phenomenon attributable to the absence of the lens, which absorbs $80 \%$ of the ultraviolet light. Glare disability in aphakes has been documented, ${ }^{10}$ " and the presence of a posterior capsule might aggravate it."

Postoperatively most of our patients complained of

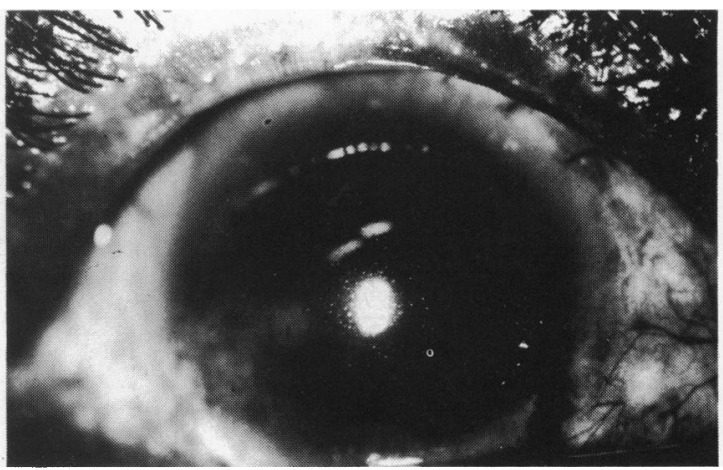

Fig. 6 Case 17, right eye eight weeks after extracapsular cataract extraction. The nodules have disappeared leaving superficial stromal scarring, LK stage 1. 
photophobia which was enhanced by the use of atropine drops and non-tinted aphakic spectacles. They also reported spending less time outdoors since their operation. The cases listed in Table 4 underwent unilateral cataract extraction, and three out of six showed concomitant regression of the LK in the fellow eye. The unoperated eyes which did not show improvement in the LK belonged to stage 2 . Operated eyes of stage 2 severity preoperatively also showed minimal improvement (Tables 2,4). The unoperated eye was not treated with any topical medication; therefore the regression of LK could not be attributed to the postoperative treatment. Since the LK regressed several weeks after the patients were discharged, hospital diet could not be the cause. The diminished oxygen requirement of an aphakic eye should be considered as a possible factor in corneal change, but the concomitant regression in the unoperated eye would remain unexplained. Another possible mechanism which could explain the regression of LK is that, following extracapsular cataract extraction, some humoral immune factors are released and influence the pathophysiology of LK. This hypothesis would need further immunological investigations.

We performed extracapsular cataract extraction because it is our preferred technique for uncomplicated senile cataracts. Whether intracapsular cataract extraction will produce the same effect will be a subject of further studies. Temporary tarsorrhaphy was considered but seemed impracticable, since LK regresses only after eight weeks of protection of the cornea. Before our observations cataract surgery was not considered beneficial for patients with moderate to severe LK, because the corneal condition was believed to be stationary or progressive, therefore improvement in visual acuity was not expected. However, our study shows that in the presence of LK and mature cataracts, lens extraction is recommended.

The LK, if not in the advanced stage 5, may regress after eight weeks of reduced exposure to UV light. This occurs after cataract extraction because these patients, under atropine, are photophobic and avoid their usual exposure to sunlight.

We are indebted to Dr P J M Bucher, from the Ophthalmology Department, Elim Hospital, in the Northern Transvaal, for his valuable collaboration in this clinical study.

\section{References}

1 Freedman A. Labrador keratopathy. Arch Ophthalmol 1965; 74: 198-202.

2 Freedman A. Climatic droplet keratopathy. Arch Ophthalmol 1973; 89: 193-7.

3 Freedman J. Band-shaped nodular dystrophy of the cornea. $S$ Afr Arch Ophthalmol 1973; 1: 149-55.

4 Freedman J. Nama keratopathy. Br J Ophthalmol 1973; 57: 688-91.

5 Fraunfelder FT, Hanna C, Parker JM. Spheroid degeneration of the cornea and conjunctiva. 1. Clinical course and characteristics. Am J Ophthalmol 1972; 73: 821-8.

6 Johnson GJ. Aetiology of spheroidal degeneration of the cornca in Labrador. Br J Ophthalmol 1981; 65: 270-83.

7 Hanna C, Fraunfelder FT. Spheroidal degeneration of the cornea and conjunctiva. 2. Pathology. Am J Ophthalmol 1972; 74: 829-39.

8 Fraunfelder FT, Hanna C. Spheroidal degeneration of cornea and conjunctiva. 3. Incidences, classification and etiology. Am J Ophthalmol 1973; 76: 41-50.

9 Johnson GJ. Histology of spheroidal degeneration of the cornea in Labrador. Br J Ophthalmol 1978; 62: 53-61.

10 Miller D, Lazenby GW. Glare sensitivity in corrected aphakes. Ophthalmic Surg 1977; 8: 54.

11 Nadler DJ, Jaffe NS, Clayman HM, Jaffe MS, Luscombe SM. Glare disability in eyes with intraocular lenses. Am J Ophthalmol 1984; 97: 43-7.

Accepted for publication 24 January 1986. 